\title{
Work in Progress: Spatial Visualization Assessment and Training in the Grainger College of Engineering at the University of Illinois
}

\section{Dr. Brian S. Woodard, University of Illinois at Urbana - Champaign}

Dr. Woodard received his Ph.D. in Aerospace Engineering from the University of Illinois at UrbanaChampaign in 2011. His Aerospace research interests currently focus on the effects of icing on the aerodynamics of swept-wing aircraft. In engineering education, he is interested in project-based learning and spatial visualization. He teaches courses at the University of Illinois where he serves as the Director of Undergraduate Programs for the Department of Aerospace Engineering.

\section{Ms. Tiffany Wenting Li}

Tiffany $\mathrm{Li}$ is a Ph.D. student in computer science at the University of Illinois at Urbana-Champaign. Her research interest lies in human-computer interaction and educational technology.

\section{Mr. Ziang Xiao}

Ziang Xiao is a Phd student from the computer science department at University of Illinois at UrbanaChampaign. His primary research interest is in human-computer interaction.

\section{Dr. Molly H Goldstein, University of Illinois at Urbana - Champaign}

Molly H. Goldstein is an engineering design educator and researcher at University of Illinois, UrbanaChampaign. She previously worked as an environmental engineer specializing in air quality influencing her focus in engineering design with environmental concerns. Her research interests include how students approach decision making in an engineering design context. She obtained her BS in General Engineering (Systems \& Design) and MS in Systems and Entrepreneurial Engineering from the University of Illinois and $\mathrm{PhD}$ in Engineering Education from Purdue University.

Dr. Michael L. Philpott, University of Illinois at Urbana - Champaign 


\title{
Work in Progress: Spatial Visualization Assessment and Training in the Grainger College of Engineering at the University of Illinois
}

\author{
Brian S. Woodard*, Tiffany Li, Ziang Xiao, Molly H. Goldstein, and Michael L. Philpott \\ University of Illinois at Urbana - Champaign \\ bswoodrd@illinois.edu
}

\begin{abstract}
Spatial visualization skills are a crucial predictor of success in STEM college majors and STEM careers. These skills can be improved with training to reduce the well-established gender difference in these skills in college-age students. This work in progress describes a preliminary analysis of data acquired regarding spatial skills on students in a college of engineering at a large, public university. Admitted freshmen students were given a standard test of spatial visualization using mental rotations. Students who were identified as having weak spatial skills compared to their peers were advised to take a half-semester visualization training course. The gender trends from the visualization assessment fit with past data, and additional race and ethnicity trends in the data are presented. Male students who are not in underrepresented minority groups generally performed the best on the assessment. The effectiveness of the spatial visualization training course was determined by giving those students the same assessment again that all of the students took initially. Overall, the course provided significant gains in spatial visualization skills to the students, consistent with past results with similar courses. This course was offered entirely online without the standard use of pencil and paper sketching. Upon closer investigation of the data, male students improved more than female students did. Further study is needed to determine if these results are representative of typical trends and how the training could be modified to result in more equitable outcomes for all the students.
\end{abstract}

\section{Introduction}

Decades of research has consistently shown that spatial skills are one of the strongest predictors of future success in STEM coursework and STEM careers independent of math and verbal ability. Wai et al. [1] and Shea et al. [2] reviewed numerous longitudinal studies with many thousands of participants to conclude that spatial skills are critical to developing expertise in STEM. Additionally, visualization skills, especially mental rotation skills, of female students are well documented to lag behind those of their male counterparts [3], [4]. Fortunately, research also shows that visualization skills are malleable, and individuals may need different methods to practice and improve their skills. Uttal et al. reviewed studies of spatial skills trainings to conclude that spatial skills trainings could enhance participation in STEM fields [5]. At the college level, Sorby showed that gender differences in STEM education could be reduced by enhancing visualization skills through training that involves different forms of practice in solving visualization problems [6]. The specifics of their visualization training for college-level students are described by Sorby and Baartmans [7]. The research team at the University of Illinois has developed an online training platform, consisting of sketching exercises and multiple-choice questions, to enhance visualization skills. This training platform was applied to students in a first-year elective course. Fifty-nine students completed the course in the fall 2020 semester. The primary elements of the course included virtual synchronous class exercises, writing reflections related to visualization skills, and weekly exercises using the training platform. Students representing eleven engineering majors registered for the class. These students were guided to the course based on the results from the Purdue Spatial Visualization Test: Visualization of Rotations (PSVT:R) which 


\section{ASEE Illinois-Indiana Section Conference Proceedings | Paper ID 35175}

is a standard instrument for measuring spatial visualization ability [8]. An electronic version of this assessment was recommended to all students entering the College of Engineering in the fall of 2020. Approximately, 1100 students completed the assessment. Students who scored below a specified threshold were recommended to enroll in the training course. The goal of the class was to improve students' visualization skills, making them more likely to be successful in STEM majors.

At this stage in the work, two preliminary data sets were analyzed. The first data set is the assessment results from the PSVT:R given to the large number of students entering the College of Engineering. The University collects additional demographic information which was analyzed in conjunction with the PSVT:R results. The other data come from the students who enrolled in the training course. In addition to their performance on the initial assessment and their class activities, they also completed the same PSVT:R assessment at the end of the class. Their performance and the overall effectiveness of the training course is evaluated. The training course was offered entirely online utilizing only computer-based tools for practicing visualization skills.

\section{Data Acquisition}

The data presented in this work come from administering the Purdue Spatial Visualization Test: Visualization of Rotations (PSVT:R) to students at the University of Illinois. This test, described by Guay in 1977, was developed to assess a person's ability to conceive what an object will look like from different perspectives [8]. This test is commonly administered by other researchers to identify weaknesses in students' visualization skills. The standard implementation of this test involves thirty multiple choice questions to be completed in twenty minutes or less. The questions involve showing an object in two different orientations, introducing a new object, and then asking what the new object would look like if rotated the same way the original object was rotated between views. Each question is multiple choice with five different answers shown. The research team implemented this test in a computer platform for easy access for students. Once the students started the test, they had to complete it within twenty minutes. Other tests of spatial ability are available, but the PSVT:R was selected due to its widespread use in other studies to which the data collected here are compared.

In 2020, the PSVT:R assessment was added to the list of recommended activities for admitted freshmen students in the Grainger College of Engineering at the University of Illinois. The PSVT:R was listed alongside standard placement exam such as those taken for Math, Physics, and Chemistry. These tests are generally completed by admitted college students near the end of their senior years in high school and before they meet with college advisors to register for freshmen classes. No students were required to complete the assessment, but the website stated that students admitted to majors requiring engineering graphics courses were strongly recommended to take the assessment. All students were encouraged to complete the assessment. As expected, many students from the majors that require engineering graphics courses completed the test, and in total, 1109 students who completed the test enrolled in engineering at the University of Illinois in the fall of 2020. Additional students completed the assessment, but they were removed from this analysis as they did not enroll in any classes at the University of Illinois for the fall semester. Figure 1 illustrates the distribution of students who completed the assessment by major. These students who completed the assessment prior to starting college are identified in the legend as "Pretest." Aerospace, Civil, Industrial, Mechanical, and Systems Engineering all require engineering graphics courses, so the large representation in the assessment was expected. However, Electrical and Computer Engineering as well as Computer Science do not require engineering graphics. Nevertheless, a large number of students in those majors also completed the pretest. Note that those are particularly large degree 
programs at the University of Illinois. The number of students completing the assessment represents approximately half of the freshman class for the fall of 2020 for the College of Engineering.

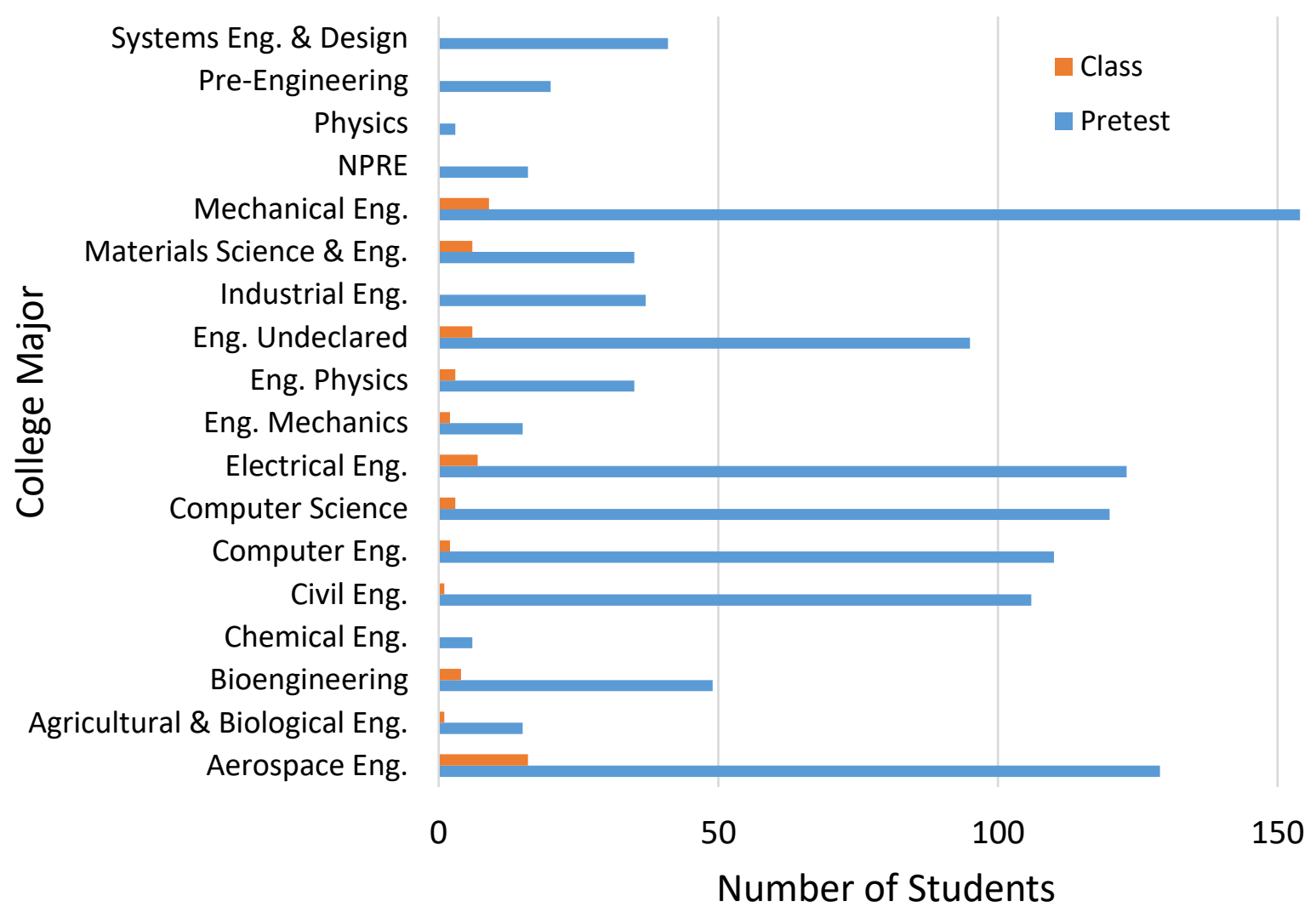

Figure 1. Number of students by major who completed the pretest assessment using the PSVT:R (Pretest) and the number who enrolled in the spatial visualization training course (Class).

A class at the University of Illinois has been developed to enhance 3D spatial visualization skills for engineers. The course is generally modeled after a similar course for freshmen students offered at Michigan Technological University and described by Sorby and Baartmans [7]. They explain both the methodology for the course at their university and a longitudinal study documenting its effectiveness. Their ten-week course includes hands-on activities as well as computer activities. The class at the University of Illinois is an eight-week course (half semester), which relies entirely on computer-based activities. Students interact with both multiple-choice questions and an online sketching tool each week. The sketching interface allows sketching on a rectangular grid and on an isometric grid. The computer interface is described by Xiao et al., but the implementation as part of a course has evolved since that publication [9]. The course does not utilize any third-party computer-aided design/drafting software.

A brief description of each week of the class is presented below:

Week 1: Introduction to the course and surfaces and solids of revolution. Students answer multiple choice questions where they identify 3D objects created by revolving a given 2D shape.

Week 2: Isometric drawings and coded plans. Students answer various multiple-choice questions with coded plans and begin using the computer-based sketching tool. They are asked to sketch objects on an isometric grid from a given coded plan. 


\section{ASEE Illinois-Indiana Section Conference Proceedings | Paper ID 35175}

Week 3: Orthographic drawing. Students are introduced to the concept of orthographic, multiview drawings. They answer multiple choice questions identifying the proper view of a 3D object. They then sketch orthographic views of objects on a rectangular grid using the computer-based sketching tool.

Week 4: Orthographic views and isometric views. Students answer multiple choice questions transforming orthographic and isometric views of objects. They create sketches using the sketching tool.

Week 5: Inclined and curved surfaces. Students work with both isometric and orthographic views of objects with inclined and curved surface in multiple-choice questions and the sketching tool.

Week 6: Cutting planes and cross sections. Students answer multiple-choice questions identifying possible cross sections from 3D objects and identifying the shape of a cross section from a given cutting plane. Students do not use the sketching tool.

Week 7: Flat patterns. Students answer multiple-choice questions where they must visualize an object that has been "unfolded" along edges and made flat. Students do not use the sketching tool.

Week 8: Rotation about multiple axes. Students answer multiple-choice questions with objects rotated about multiple axes. They identify the object after multiple rotations and also identify the axes about which an object has been rotated. The students utilize the sketching tool to create isometric sketches of objects that have been rotated about multiple axes.

With the data from PSVT:R assessment for many freshmen students, engineering advisors were asked to recommend students who failed the assessment to take the spatial visualization course during their first semester of college. Failure is considered to be a score of 18 or less on the thirty-question test. This cutoff is consistent with past studies that utilized the same preassessment. The course is not required for any major, so students were not forced to take the class. Advisors were provided with a brief explanation of the potential benefits of the course to share with the students who could benefit from enrolling in it. The class is only one credit hour, so it is assumed that most students would be able to add it to their schedules. Students who enrolled in the course were also recommended, if possible, to take their required engineering graphics course during the second semester of their freshmen years. Of the 1109 students who completed the assessment, 237 scored eighteen or lower. Fifty-nine students enrolled in the spatial visualization training course. The distribution of majors is also shown for those 59 students in Fig. 1. Aerospace and mechanical engineering were the two majors representing the majority of students in the class. While spatial skills are important for those majors, these skills are also crucial to other majors. The authors are not certain about the cause of the distribution of students, but it may have been simply related to advising differences between the majors during summer registration. At the end of the course, the students were again asked to take the PVST:R assessment. Forty of the students enrolled in the course took both the pretest and the posttest assessments. Of the 59 students in the course, 5 students enrolled without taking the pretest, and 14 students did not complete the posttest. Of the remaining 40 students in the class, 30 of them scored 18 or less on the pre-test. The course could not be restricted based on the score of an optional test. Ultimately, many students who might have benefited from the class did not take it, and some students who may not have needed the visualization practice, did take the course.

The class consists of nine weekly one-hour sessions. The sessions are held virtually and synchronously. For most weeks, a short lecture-style presentation was given in order to introduce the topic for the week. The rest of the time was spent with the students performing introductory tasks in the online sketching environment. They took turns sharing their screens and assisting each other with the virtual sketching tasks. These class interactions accounted for a small amount of the course grade. The majority of the grade was associated with completing the online training modules described previously. Short reflections were also a required part of the course. The students read articles or watched videos related to visualization or visualization training, and then wrote $200-300$ words about their reactions. Three of these assignments 
were required throughout the course. The effectiveness of this entirely virtual course is based on the preand post-assessments using the PSVT:R.

\section{Results and Discussion}

As described above, two related, but different, data sets are analyzed here. The PSVT:R data collected from the 1109 students who completed the assessment before enrolling in the University can be investigated along with additional demographic information collected by the University. The pre- and post-test data for the students who enrolled in the spatial visualization course can be analyzed to assess the effectiveness of the spatial visualization training course.

Table 1 summarizes the results from the PSVT:R administered to the large group of freshmen students. As stated before, the maximum score on the PSVT:R test is 30. The table shows the number of students in each group and the percentage of the overall group made up by the subgroups. These data are consistent with past work showing that freshmen college student males generally score approximately three questions better than females on this assessment [6]. The distribution of scores is shown in Fig. 2 for all students. The students who failed the test by scoring 18 or less can be seen as compared to the entire group. The vast majority of the students scored well on the test with thirty-one students earning a perfect score.

Table 1. Summary of PSVT:R pre-test assessment

\begin{tabular}{|l|c|c|c|}
\hline & All Students & Male & Female \\
\hline PSVT:R Mean Score & 22.4 & 23.2 & 20.1 \\
\hline Number of Students & 1109 & 820 & 289 \\
\hline$\%$ of Students & $100 \%$ & $73.9 \%$ & $26.1 \%$ \\
\hline
\end{tabular}

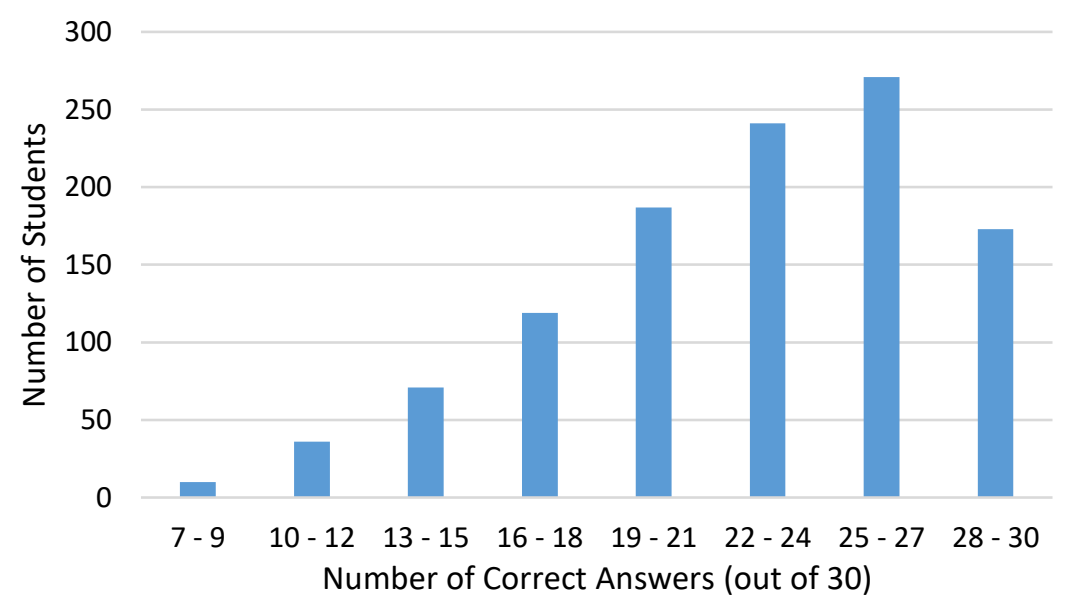

Figure 2. Distribution of scores on the PSVT:R test for all students showing the number of students in each category.

The University collects additional demographic data which was provided to the research team matched to the PSVT:R scores. The information in these categories was provided by the University and was not collected as part of the assessment. Figure 3 shows the distribution of scores on the test broken out by gender and shows the percentage of the group rather than the number of students for each bin of test scores. This plot better illustrates the differences between the male and female students since the number of male and female students was significantly different as listed in Table 1. The peak of the distribution for female students is $19-21$ (23.5\% of the female students) while the peak for the male students is $25-27$ ( $24.5 \%$ of 
the male students). Similar data are plotted in Fig. 4 related to the race and ethnicity of the students. The data provided to the researchers simply grouped all international students into one category, so that one category is presented in the figure. The number of international students represented is 118 . Three categories of race and ethnicity were combined to create the category of under-represented minorities (URM) in engineering. Black or African-American, Hispanic, and Native Hawaiian and Pacific Islander students are combined in the category of URM. The number of URM students is 124 . The remaining students were categorized as non-URM. As with the previous plot, the percentage of the group is shown for each bin as the number of students in each category is significantly different. Male and female students are grouped together in this plot. On average, the international students' PSVT:R scores (22.3) almost exactly match the average from all of the students. The non-URM group had an average score of 22.6, slightly higher than the entire group average. The URM group's average score was 21.4 , which is half way between the average score for the male and female groups on the assessment. The URM and female students, which are already underrepresented in engineering, have less developed spatial visualization skills making it more likely they will struggle in subsequent courses. Identifying these students provides an opportunity to assist them with their spatial skills and increase their chances of success in engineering.

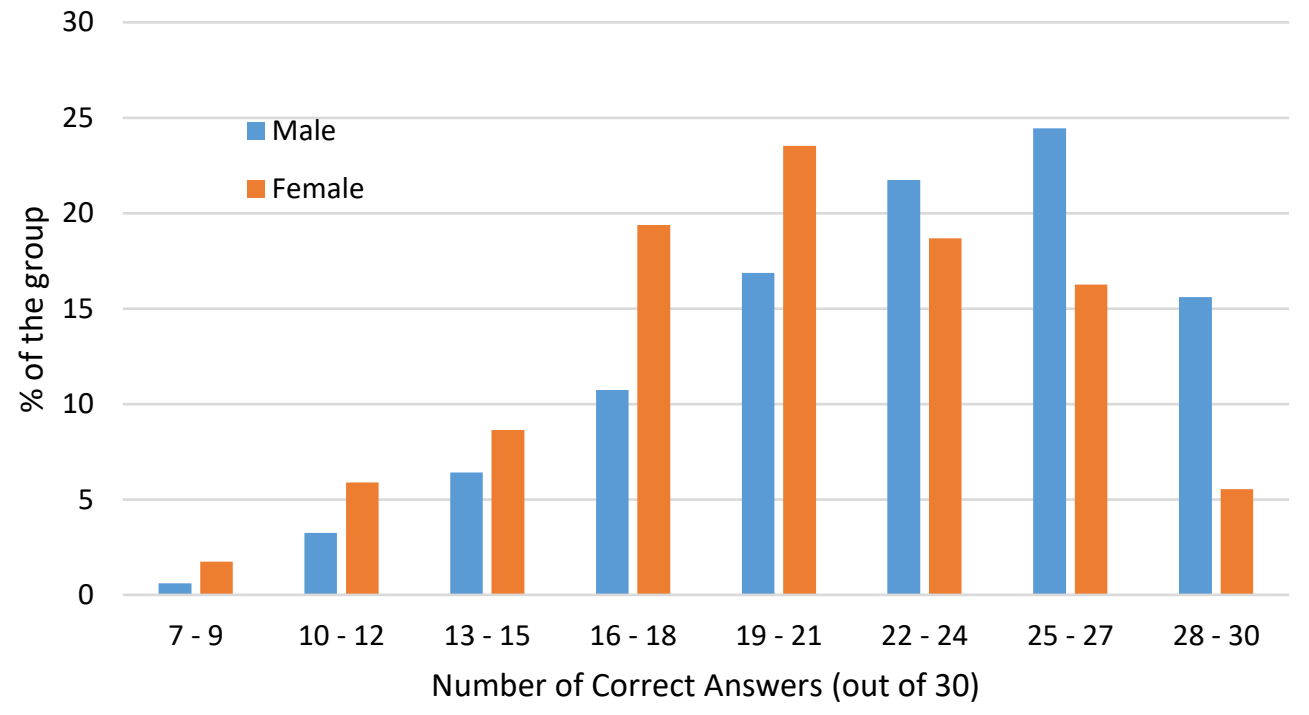

Figure 3. Distribution of scores on the PSVT:R test showing the difference between male and female students as a percentage of each of their groups. 


\section{ASEE Illinois-Indiana Section Conference Proceedings | Paper ID 35175}

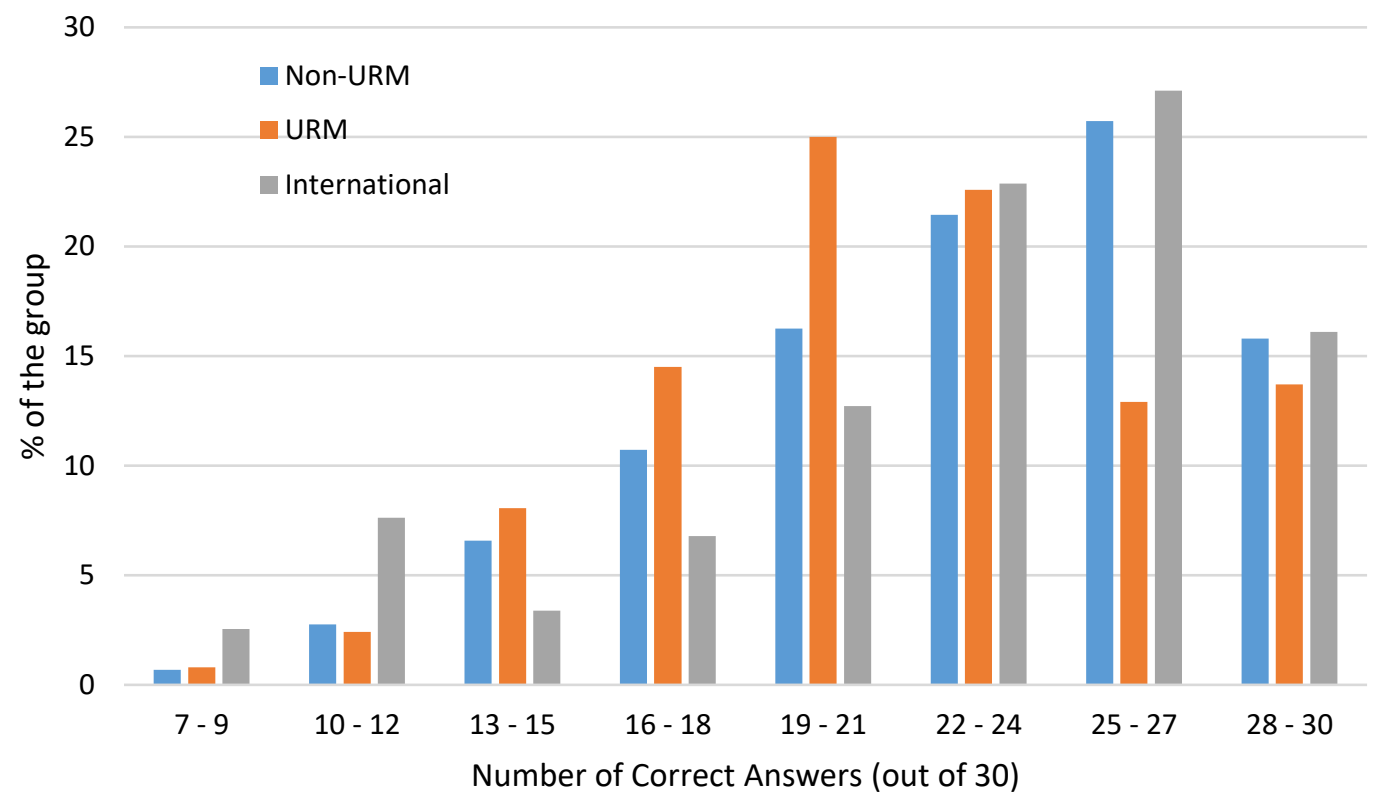

Figure 4. Distribution of scores on the PSVT:R test showing the difference between non-URM, URM, and international students as a percentage of each of their groups.

As described in the previous section, 40 of the students who enrolled in the spatial visualization training course completed both the pre- and post-assessment. Twenty-one of those students identified as male and 19 as female. Of those students, 30 scored eighteen or lower on the pretest. The results from the pretest and posttest are shown in Fig. 5. The average improvement by the students enrolled in the course is significant, even when including the entire class. The average pretest score was 16.5 , and the average posttest score was 22.4. Looking at only the students who scored less than or equal to 18 on the pretest, the average improvement is even more dramatic. The average pretest score was 14.3 for those students, and the average posttest score was 21.4 , making an improvement of nearly $50 \%$ on average for those students. This impact from a visualization training class on the PSVT:R results are consistent with past work [7]. These results are particularly encouraging as they were accomplished in an entirely virtual environment. The computer-based sketching environment may be a sufficient replacement for hand sketching to improve visualization skills. Previous work with engineering students at Michigan Technological University included pencil and paper sketching exercises, which are difficult to scale to large class sizes. These results are encouraging to continue to evaluate the use of the computer-based sketching tool. 


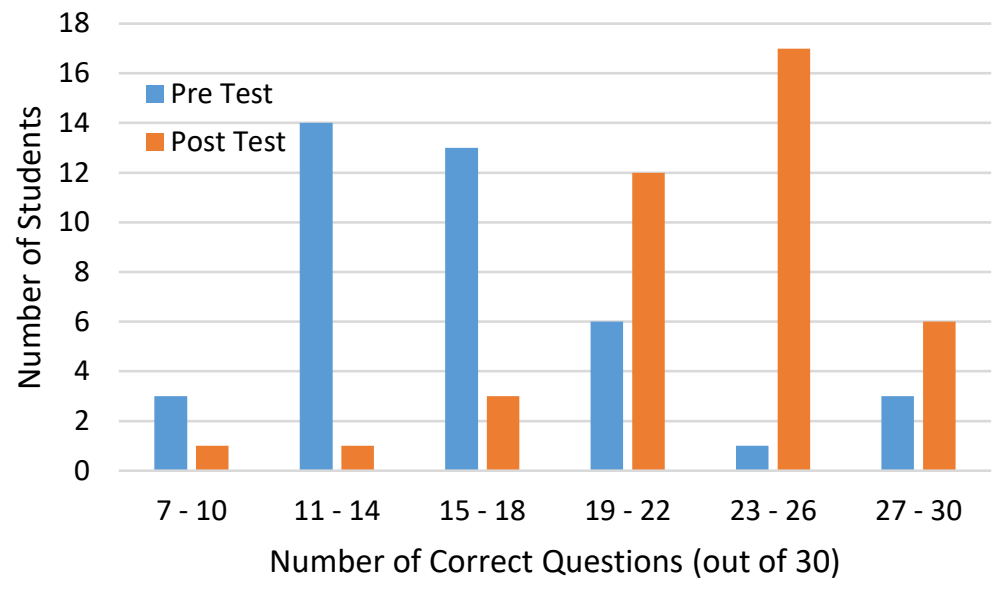

a)

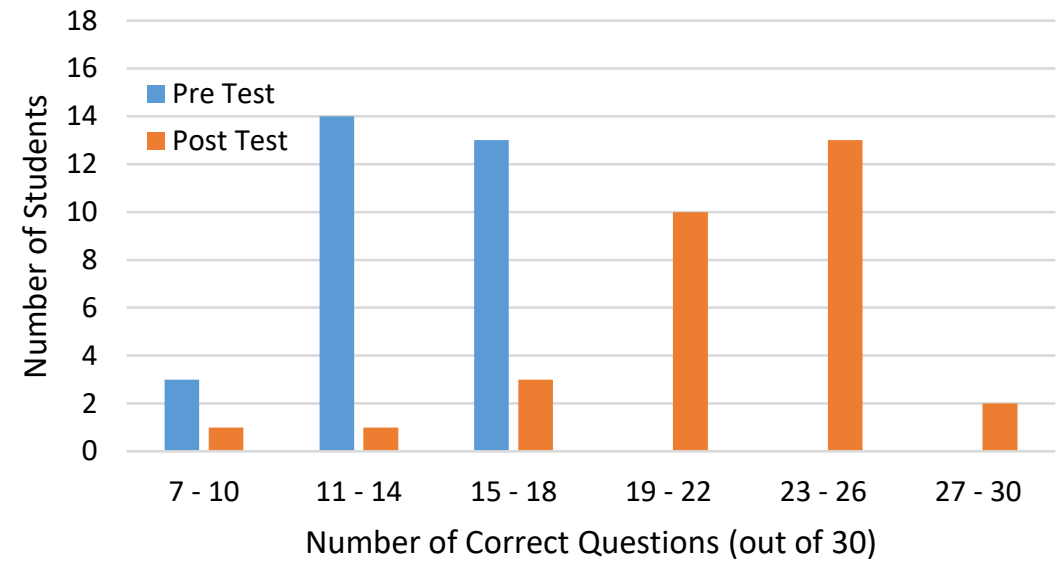

b)

Figure 5. Number of students scoring in each bin range on both the PSVT:R test before and after the visualization training course. The data from the entire class is shown in a), and in b) only the data for the students who started with scores less than or equal to 18 are shown.

A further analysis of the data from the students who scored less than or equal to 18 on the pretest identified a concerning trend associated with gender. Figure 6 shows the improvement on the PSVT:R from before and after the training class divided by gender. The bins in this figure were set to include a single value of improvement in order to illustrate the observed trend. The average improvement is not evenly distributed by gender. The male students improved significantly more than the female students did. On average, the improvement for this group of male students was 9.1 questions where the female students improved by 4.8 questions. The number of female (14) and male (16) students was similar, so the actual number of students is shown in Fig. 6. Table 2 summarizes these results. This trend deserves further investigation and consideration when future data sets are acquired and analyzed. 


\section{ASEE Illinois-Indiana Section Conference Proceedings | Paper ID 35175}

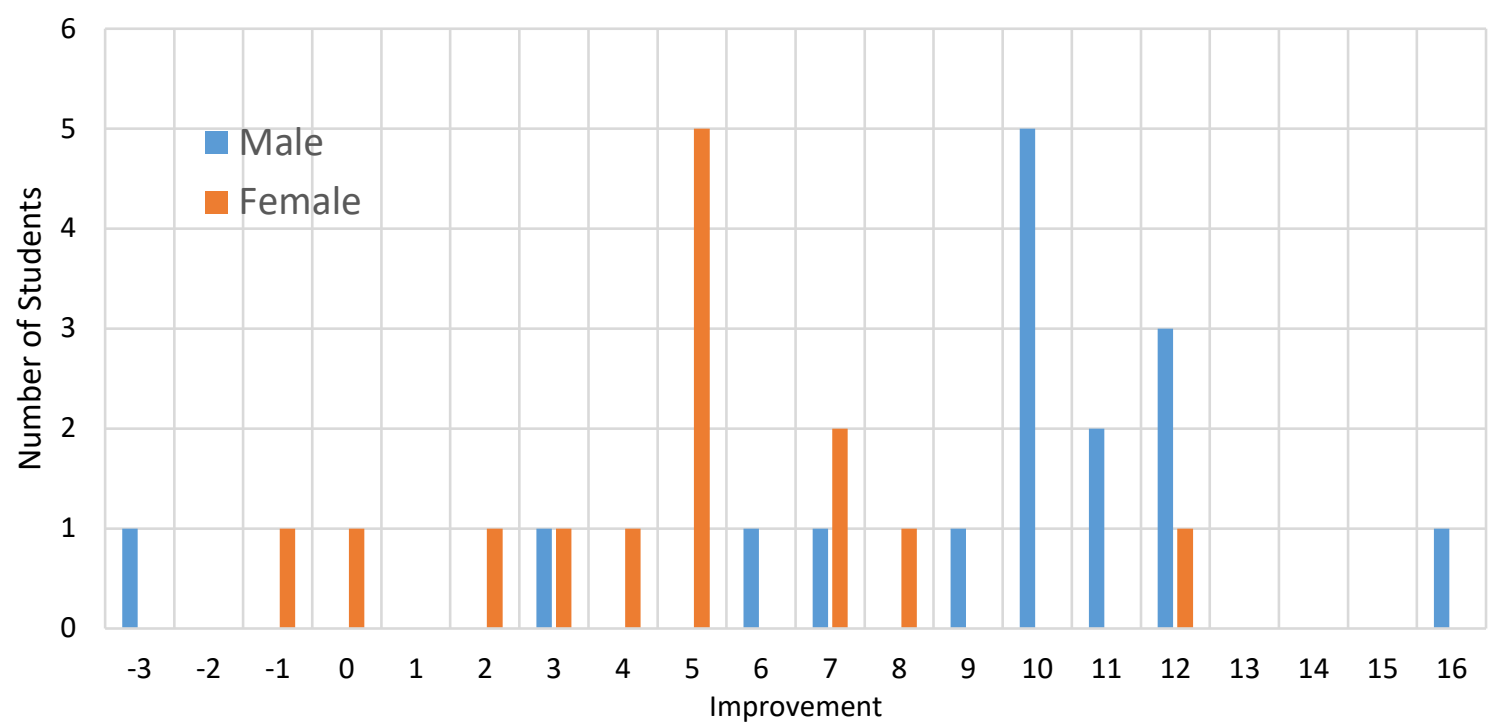

Figure 6. Number of students in each bin of improvement from pretest to posttest score on the PSVT:R divided by gender. Data only shown for students who scored less than or equal to 18 on the pretest.

Table 2. Average PSVT:R results for pretest and posttest divided by gender for students who scored less than or equal to 18 on the pretest.

\begin{tabular}{|l|c|c|c|c|}
\hline & Number of Students & Pretest & Posttest & Improvement \\
\hline Male & 16 & 13.9 & 23.0 & 9.1 \\
\hline Female & 14 & 14.7 & 19.5 & 4.8 \\
\hline
\end{tabular}

\section{Summary and Conclusion}

This paper summarizes and presents preliminary data associated with a spatial visualization training course in a large, public college of engineering. Significant past research has demonstrated the importance of visualization skills to the success of students in STEM careers. These effects have been documented regarding visualization skills in both college-age students and younger student in longitudinal studies. Additionally, the visualization skills of female students are not as well developed as their male counterparts, especially in the area of mental rotations. Other universities have implemented programs for supporting students with lower visualization skills during their first semester of college. The Grainger College of Engineering at the University of Illinois implemented a half-semester course for training visualization skills during the fall semester of 2020. In contrast to other visualization training courses, this course was offered entirely online, utilizing a computer-based sketching tool in place of the traditional paper and pencil sketching. The investigation of the online modality was originally motivated by the need to teach the class to a large number of students and was further necessitated by the ongoing pandemic.

In order to identify students who would benefit from visualization training, the PSVT:R was made available to all new students admitted to the college of engineering for the fall of 2020. Approximately half of the admitted students completed the assessment. The assessment was recommended but not required. Of those students, 237 were identified as having significantly lower visualization skills than their peers. Fifty-nine of those students enrolled in the elective course for improving visualization skills. The course primarily requires students to interact with an online training platform to answer multiple-choice questions and perform online sketches. The sketching tool allows students to sketch on an isometric or rectangular grid, and it provides automated feedback to the students as they progress through the lessons. The class also 


\section{ASEE Illinois-Indiana Section Conference Proceedings | Paper ID 35175}

includes synchronous class meetings where students are introduced to topics and practice using the sketching tool. A few short writing assignments are additionally utilized by the class to educate students about the importance of their visualization skills.

The PSVT:R assessment has been administered to the large number of freshmen students at the University of Illinois for the first time. It is planned to follow to the same procedure in 2021. Similarly, the online visualization course has only been offered to a large number of students one time. Nevertheless, the preliminary data provide an interesting foundation for continued studies. The large data set from the freshmen PSVT:R was combined with University-collected demographic data. The genders, majors, and race and ethnicity of the students was combined with their PSVT:R scores. The differences between male and female students was consistent with previous research studying similar groups of students of the same age. Male students scored approximately 3 questions better on the test on average. The PSVT:R results were also investigated divided into three categories of domestic underrepresented minorities in engineering, domestic non-underrepresented minorities in engineering, and international students. The nonunderrepresented minorities group and the international group performed similarly well on the test. The underrepresented minorities group performed approximately 1.5 questions worse than the nonunderrepresented minorities and international students. The distribution of scores on the PSVT:R for each of these groups is presented. Previous work by Levine et al. considered the interaction between socioeconomic status and gender differences in visualization skills for younger students [10]. Further research could be performed by looking even further in to the demographic data for these college students to identify whether similar trends exist.

The students who enrolled in and completed the spatial visualization training course were given the PSVT:R test again at the end of the course to assess the effectiveness of the training. Thirty students who scored 18 or less on the pretest enrolled in the course and completed the posttest. The pretest and posttest scores are presented with excellent improvement indicated on average for the class. Students improved by 7.1 questions on average when they took the PSVT:R at the end of the course. This result is consistent with other visualization training courses. The training course utilizing a computer-based sketching tool appears to be equally effective to courses training visualization with pencil and paper sketching exercises. If confirmed with additional data, this result is encouraging for teaching large-scale classes and for remote education. A further investigation of the data revealed that the improvement on the assessment was not evenly distributed by gender. While all students on average improved, the male students improved significantly more than the female students did. These results require more data to confirm and investigate to determine if the type of training provided is actually more effective for male students, and if so, whether the training can be adjusted to provide equal effectiveness for all students.

The research here is presented as a Work in Progress as the data only represent one iteration of the process of testing students and performing spatial visualization training. Additionally, this one year of data was collected during a pandemic, which may result in other factors influencing the performance of the students studied. The research team intends to continue this study. The pretest PSVT:R will be available to admitted freshmen students again, and the visualization training course will be offered during the fall of 2021 .

\section{Acknowledgements}

The authors thank the many individuals and organizations that contributed to the success of this project over the past several years. The project was directly supported by an internal grant through the Strategic Instructional Innovations Program in the Grainger College of Engineering at the University of Illinois. 
Marcia Pool provided outstanding advice throughout the project, and Gretchen Forman, Julia LaystromWoodard, and Angie Wolters made various supporting contributions as well Additionally, several undergraduate students generated the banks of questions and answers for the online training platform. Kirk Leck, Krishna Modi, Richard Mauge, and Robert Mauge are thanked for that contribution.

\section{References}

[1] Wai, J., Lubinski, D., and Benbow, C.P. (2009) Spatial ability for STEM domains: Aligning over 50 years of cumulative psychological knowledge solidifies its importance. Journal of Educational Psychology 101, 4, 817-835.

[2] Shea, D.L., Lubinski, D., and Benbow, C.P. (2001) Importance of assessing spatial ability in intellectually talented young adolescents: A 20-year longitudinal study. Journal of Educational Psychology 93, 3, 604-614.

[3] Linn, M. C. and Petersen, A. C. (1985). Emergence and characterization of sex differences in spatial ability: A meta-analysis. Child Development 56 (1985) 1479-1498.

[4] Voyer, D., Voyer, S. and Bryden, M. (1995) Magnitude of sex differences in spatial abilities: A meta-analysis and consideration of critical variables. Psychological Bulletin, 117, 250-270.

[5] Uttal, D. H., Meadow, N. G., Tipton, E., Hand, L. L., Alden, A. R., Warren, C., \& Newcombe, N.S. (2012, June 4). The Malleability of Spatial Skills: A Meta-Analysis of Training Studies. Psychological Bulletin. Advance online publication. 10.1037/a0028446

[6] Sorby, S.A., (2009) Educational Research in Developing 3-D Spatial Skills for Engineering Students, International Journal of Science Education, 31:3, 459-480, DOI: $10.1080 / 09500690802595839$

[7] Sorby, S.A., \& Baartmans, B.J. (1996). A course for the development of 3-D spatial visualization skills. Engineering Design Graphics Journal, 60(1), 13-20.

[8] Guay, R.B. (1977). Purdue spatial visualization test: Rotations. West Lafayette, IN: Purdue Research Foundation.

[9] Xiao, Z., Yao, Y., Yen, C., Dey, S., Wauck, H., Leake, J. M., Woodard, B., Wolters, A., and Fu, W. (2017) A Scalable Online Platform for Evaluating and Training Visuospatial Skills of Engineering Students Paper, 2017 ASEE Annual Conference \& Exposition, Columbus, Ohio 10.18260/1-2_27509.

[10] Levine, S.C., Vasilyeva, M., Lourenco, S.F., Newcombe, N.S., and Huttenlocher, J., (2005) Socioeconomic Status Modifies the Sex Difference in Spatial Skill, Psychological Science, 16 (11), 841-845. 